\section{A NEW BATH.}

WE have had an account furnished to us of a convenient bath, invented by Mr. Gilbert, of Stamford, which appears likely to supersede the common baths now in use. The chicf thing aimed at in the construction of the new bath, is so to arrange its shape as to admit of complete immersion with the smallest possible quantity of water, and the accomplishment of this ensures other advantages, such as tightness, portability, \&c.

In ordinary circumstances, it is a matter of great convenience to be able to procure a bath readily; but in violent and sudden attacks of disease, where life may be in peril, the prompt application of the bath is of vital importance, and this paramount advantage is secured by the invention, five gallons only of boiling water being sufficient to make a bath of 103 for the immersion of the whole body up to the chin. To get in and out of a bath with facility, or be readily assisted when too weak, is no inconsiderable advantage, and this is secured by the invention, the position of the body in using it admitting of the bath being made so much lower than those hitherto in use. The ease with which the bath can be moved about the room, without noise or bustling ceremony, is ensured by this bath being placed on castors. A comfortable and safe position while using the bath is no inconsiderable desideratum, and this is insured by the patient being obliged to adopt the recumbent posture, with the knees flexed.

In the treatment of diseases of certain locality, waters of different temperature for the hips and feet may be advantageous; and the simple shape of this bath, without any further contrivance, will permit such arrangement.

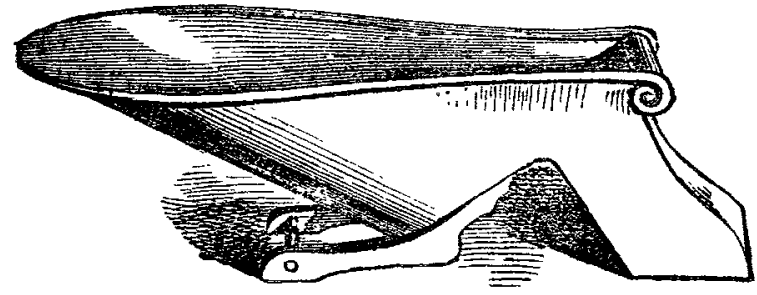

By means of a tube running underneath, and connecting the two compartments of the bath, the same level and temperature can be preserved in both, and the water may be made to flow readily from one to the other in emptying the bath. By means of a plug, the two compartments may be rendered distinct, so to form a hip-bath or a foot-bath separately, or a hip-and-foot bath simultaneously at different temperatures. We believe Mr. Gilbert's very ingenious in vention has been highly approved of at Guy's and St. Bartholomew's Hospitals.

\section{LIFE ASSURANCE OFFICES AND THE MEDICAL PROFESSION.}

\section{To the Elitor of THE LANOET}

Westminster and General Life Assurance Association, 27, King Street, Covent Garden, 24th Oct. 1848.

Srn, - I am instructed to inform you, that the directors of this Association, having taken into consideration the trouble and responsibility incurred by the medical profession in furnishing, to Life Assurance Companies, their opinion as to the eligibility of the lives of their patients for assurance, have decided upon allowing a fee of $1 l .1 s$. to every medical referee who shall give a certificate, in reply to an application from the office of this Association.

I beg leave to remain, Sir, your most obedient servant, Wm. Browne, Actuary.

MEDICAL TREASON IN A POOR-LAW UNION. DOINGS IN LLANEROHYMEDD DISTRICT OF THE ANGLESEY UNION. To the Editor of The LANCET.

Sir,-You will much oblige me by giving publicity to the following facts. Having been summoned by the clerk of the guardians, along with the other medical officers belonging to the union, to attend at the board-room at Llanerchymedd, on Wednesday, the 25 th instant, at twelve o'clock, to enter into a fresh contract with them for the ensuing year, (as is the universal practice in the different unions in the Kingdom), I attended; but judge of my surprise, when I was told by one of the guardians, that the board had that morning received a tender from another medical man, residing in the aame village with myself, and sent in by him, with an intention of depriving me of the appointment which $I$ have held for the last two years.

The chairman, when I went in to the meeting, informed me that the board did not think it necessary to advertise for fresh candidates, as they were perfectly satisfied with their present medical officers. Allow me to mention, further, that this medical man is an utter stranger to this part of Wales, and it is only about nine months back since he came to reside here. I will only add his name, Richard L. Parry; he was, I believe, lately practising in Liverpool.

I leave it to my professional brethren to judge if such conduct is worthy of any one pretending in the least to call himself a gentleman, much less a brother in the same honourable profession. Acknowledging the value of your able advocacy in the cause of justice to medical men, in whatever situation they may be placed,

I am, Sir, your most obedient servant,

Llanerchymedd, Oct. 1848. H. Beaver DAviEs, M.R.C.S.E

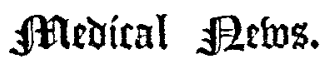

Royal Colugge of Surgeons.-The following gentlemen having undergone the necessary examinations for the diploma, were admitted members of the college, at the meeting of the Court of Examiners, on the 3rd instant:-

Codlcher, Martin Wales Bedell, Downham, Norfolk.

Elkington, John, Birmingham.

Falconer, John, Edinburgh.

Ham, William Birds, Liskeard, Cornwall.

Marsack, Blackall, Reading, Berkshire.

Newham, Thomas, Northampton.

Pellegrin, Jean Felix, The Mauritius.

At the same meeting of the court, Messrs Jorn Sale and Fomund Lawless, passed their examinations for full surgeons in the Royal Navy : these gentlemen had previously been admitted members of the college, the diploma of the former bearing date July 26, 1844, and that of the latter August 16, 1844 .

Royal. Sea-Bathing Infirmary.-The 53rd Anniversary Dinner of subscribers to the Royal Sea-bathing Infirmary at Margate, took place on Tuesday, Oct. 31 , in the London Coffeeroom, Ludgate-hill; the Lord Mayor in the chair. The object of the institution is to afford relief in cases of scrofula; the patients now exceed 700 . It appeared that $116 \mathrm{l}$. had been re ceived from church collections in the present year. The donations and subscriptions for the evening amounted to $582 l$, besides $311 l$. subscribed at Margate. In the course of the proceedings, it was stated by Mr. Coulson that this was the only institution of the kind in existence; and from the hereditary nature of the disease which it was intended to meet, the Infirmary was not only of immediate benefit to in. dividuals, but was calculated to prove of the utmost advantage to the nation at large.

We are informed by a correspondent, that Professor Cloquet has recently visited this Infirmary, having been deputed by many of the inhabitants of Paris and of Lyons to inquire into the: medical and other arrangements of the institution, in order that a similar establishment should be erected on the French coast, probably at Marseilles. Mr. Waddington, the consulting surgeon, and $\mathrm{Mr}$. Field, the resident surgeon of the Infir mary, had the honour of lengthened interviews with the learned professor, (who was accompanied by his accomplished wife, an English lady, ) and who expressed himself highly gratified with the internal arrangements of the institution, but was greatly surprised at finding that the Infirmary, the only one in England, was closed from the middle of October until the middle of May; and that the patients paid for their board! The feeling is every day getting more and more strong in favour of the Infirmary being kept open all the year; and it is whispered that J. A. Warre, Esq., high sheriff of Kent, together with two ex-sheriffs, Sir M. Montefiore, Bart., and J. P. Powell, Esq., of Quex-park, have it in contemplation to call a meeting of the inhabitants of the Isle of Thanet to forward so excellent an undertaking. This is certain-show Englishmen the necessity, and they will supply the means. It appears that the Royal Sea-bathing Infirmary has been at work fifty-six years, during which time, nearly twenty thousand patients have partaken of its benefits; and $y$ et its funds are at $a$ low ebb. If the greater number of patients had been cured, a liost of benefactors would have risen $u p$, and surely it would not have remained the ouly institutiou of the kind in England! 